\title{
Chronic Antibody Mediated Rejection of Renal Allograft - Efficacy of Combined Treatment with Plasma Exchanges, Intravenous Immunoglobulin and Rituximab (One Center Experience)
}

\section{Stolyarevich ES ${ }^{1-3}$, Artyukhina LA ${ }^{3}$, Zakharova $\mathrm{EV}^{2^{*}}$ and Tomilina NA ${ }^{1-3}$}

${ }^{1}$ Federal Center of Transplantology and Artificial Organs n.a V.I. Shumakov, Moscow, Russian Federation

${ }^{2}$ Nephrology Chair, Moscow State University of Medicine and Dentistry, Moscow, Russian Federation

${ }^{3}$ Moscow City Hospital \#52, Moscow, Russian Federation

\begin{abstract}
Chronic antibody mediated rejection (CAMR) is the main cause for late kidney transplant loss, and the results of its treatment are dissatisfying. In our one center study we evaluated the efficacy of combined treatment with plasma exchanges, intravenous immunoglobulin and rituximab on the top of standard immunosuppression in 24 patients with chronic transplant glomerulopathy (TG), compared to control group of 26 patients, who did not receive additional treatment. At the time of diagnosis baseline estimated glomerular filtration rate (eGFR) did not differ between treatment and control subgroups $(44.9 \pm 21.3 \mathrm{vs} 41.2 \pm 14.6 \mathrm{ml} / \mathrm{min}, \mathrm{P}=0.47)$, as well as any other laboratory or pathology data, and subsequent decline of allograft function was also found in both subgroups. However, the rate of eGFR decline was significantly lower in the patients from the treatment subgroup compared to the controls: $-0.47 \pm 0.6 \mathrm{ml} / \mathrm{min} / \mathrm{month}$ and $-1.31 \pm 1.6 \mathrm{ml} / \mathrm{min} / \mathrm{month}$ respectively $(P=0.02)$. Thus 3 -year transplant survival turned to be $21.3 \%$ in the control subgroup vs $64.8 \%$ in the treatment subgroup $(p=0.01)$. Our study demonstrated, that TG, which is the most often variant of CAMR, is characterized by unfavorable prognosis regardless of its pathology features and activity at the time of diagnosis. Combined treatment, including plasma exchanges (PE), intravenous immunoglobulin (IVIG) and rituximab (Rtx) allows slowing down the rate of the disease progression at least in some proportion of patients with lately diagnosed CAMR.
\end{abstract}

Keywords: Chronic antibody-mediated rejection; Transplant glomerulopathy; Plasma exchanges; Intravenous immunoglobulin; Rituximab

\section{Background}

Long-term renal transplant (RT) survival is in the focus of interest of many studies over last decades. Recent data indicate, that antibody mediated rejection (AMR), most often presenting as TG, is the main cause for late kidney transplant loss. Early stages of AMR are characterized by inflammatory microvascular lesions with inflammatory cells retention in the glomerular and peritubular capillaries (PTC). These lead to endothelial cell damage and subsequent capillary walls remodeling with double-contour pattern, and dissection of PTC basement membrane, which are characteristic for chronic antibody mediated rejection (CAMR) [1,2].

Above-mentioned pathology features, along with complement $\mathrm{C} 4 \mathrm{~d}$ expression and presence of donor specific antibodies (DSA) represent AMR diagnostic spectrum. Importantly, microvascular inflammation may preclude or coexist with chronic lesions [3-6]. Finding of even few double-contour capillary loops confirm the diagnosis of CAMR, considered as active if C4d staining on PTC is positive. Thus, acute AMR, as well as active and non-active CAMR, reflect consecutive stages of the single process, which lead to the kidney transplant dysfunction and finally to the loss of renal allograft.

However, treatment efficacy and prognosis in acute and chronic AMR significantly differ. Conventional therapy for AMR is directed to pre-existing DSA elimination and their production blockade. Several studies demonstrated that combined therapy, including PE, high dose IVIG and Rtx, was an effective treatment for acute AMR [7-10]. Unfortunately, the results of CAMR treatment are dissatisfying. Only few small studies with controversial results are published so far [1115]. Despite the treatment efficacy in these patient series is not clear, all authors stress stabilization of transplant function even in patients with advanced chronic lesions, including TG. According to the Moscow
Nephrology Centre Renal Biopsies Registry (data published in Russian) CAMR was diagnosed in 171 cases out of 1360 kidney transplant biopsies over last 10 years, which constituted $12.6 \%$. CAMR was found mostly late (mean time after transplantation $85.5 \pm 59.5$ months). In cases when transplant biopsy was performed as late as in $>5$-year posttransplant period, CAMR frequency turned to be $23.6 \%$ (99 out of 420 biopsies). 5 -year transplant survival in cases of CAMR was $26 \%$. We aimed to evaluate efficacy of PE, IVIG, and Rtx combination for treatment of late TG.

\section{Materials and Methods}

Study group included 50 patients (mean age $40.6 \pm 12.5$ years, M/F ratio - 30/20), with pathology proven chronic TG, diagnosed lately after renal transplantation - median follow-up after transplantation 81.4 [7.3; 285.0] months. In all cases indication for transplant biopsy was allograft dysfunction (mean serum creatinine $0.21 \pm 0.08 \mathrm{mmol} / \mathrm{l}$ ), isolated, or in combination with proteinuria (mean protein excretion $2.1 \pm 1.9 \mathrm{~g} /$ day). Diagnosis of CAMR was based on pathology features of TG along with at least one of the following symptoms: C4d positivity on PTC, and/or presence of anti-HLA antibodies. Patients with only TG by pathology without C4d+ or DSA were excluded from the study [6]. Vast majority of subjects $(n=44)$ received conventional 3-drug therapy,

*Corresponding author: Elena Zakharova, Nephrology Chair, Moscow State University of Medicine and Dentistry, Moscow, Russian Federation, Tel: +7 967 134 6936; E-mail: helena.zakharova@gmail.com

Received: March 10, 2016; Accepted: March 29, 2016; Published: April 05, 2016

Citation: Stolyarevich ES, Artyukhina LA, Zakharova EV, Tomilina NA. (2016) Combined Treatment with Plasma Exchanges, Intravenous Immunoglobulin and Rituximab (One Center Experience). J Nephrol Ther 6: 243. doi:10.4172/21610959.1000243

Copyright: (C) 2016 Stolyarevich ES, et al. This is an open-access article distributed under the terms of the Creative Commons Attribution License, which permits unrestricted use, distribution, and reproduction in any medium, provided the original author and source are credited. 
including cyclosporine- $\mathrm{A}(\mathrm{n}=28)$ or tactolimus $(\mathrm{n}=16)$ in combination with steroids (all) and mycophenolates $(n=41)$ or azathioprine $(n=3)$. 2 patients received proliferative signal inhibitor (everolimus)-based 3 -drug therapy, and 4 patients got 2-drug therapy with cyclosporine-A and steroids.

Depending on the additional treatment regimen, we selected two subgroups: treatment subgroup, including 24 patients treated with PE+IVIG+Rtx on the top of standard therapy; and control subgroup, comprised of 26 patients, who did not receive any additional therapy.

Pathology examination of renal allografts cores included light microscopy with H\&E, PAS and Masson-trichrome staining. Pathology evaluation was based on Banff classification [3]. TG was diagnosed if double-contours were found in $>10 \%$ of capillary loops in at least one glomeruli (Banff cg1). C4d staining was performed on cryo-sections by indirect immunofluorescence with FITC-conjugated anti-C4d monoclonal antibodies (Quidel Corporation, San Diego, CA). Staining was considered as diffuse in cases with C4d expression on $>50 \%$ of PTC, and focal in cases with C4d expression on 10-50\% of PTC [3]. All patients were tested for anti-HLA antibodies class I and II by ELISA or Luminex method.

\section{Patient's characteristics}

31 out of 50 patients presented with all three symptoms (TG by pathology, C4d-positivity and anti-HLA antibodies), and were diagnosed with active CAMR. Other 15 had C4d-negative chronic rejection in presence of DSA; and in the rest 4 cases we did not find any anti-HLA antibodies at the time of biopsy, despite clear evidence of TG and diffuse staining for C4d on PTC. Severity of TG was considered as minimal, moderate and prominent in 24, 20 and 6 cases respectively. Complement C4d staining was diffuse in 26 and focal in 9 out of 35 C4d-positive cases. 13 patients demonstrated also features of acute cell-mediated rejection - interstitial (7 cases) or vascular (6 cases). Anti-HLA antibodies were mostly represented by class II (class II only, found in 30 patients; or class II plus class I - in 12 patients), and just 4 patients had anti-HLA antibodies class I only. Laboratory findings and pathology characteristics are shown in the (Table 1). As one can see from the table, there were no differences between the subgroups at the time of rejection diagnostics.

\section{Treatment protocol}

After the pathology confirmation of CAMR, patients, receiving 2-drug therapy and 3-drug therapy based on cyclosporine or everolimus, were converted to unified 3-drug therapy: tacrolimus plus mycophenolates plus steroids. Patients with concomitant cell-mediated rejection (which was found in 13 cases) received 3 methylprednisone i.v. pulses, $250-500 \mathrm{mg}$ per pulse. Subsequently on top of this therapy 22 patients from treatment subgroup received combination of $\mathrm{PE}$ (№ 4-6), IVIG (0.5-1 g/kg) and Rtx (single dose $500 \mathrm{mg}$ ), another 2 patients from treatment subgroup with $\mathrm{C} 4 \mathrm{~d}$-negative rejection, manifested with isolated proteinuria, received IVIG $0.5 \mathrm{mg} / \mathrm{kg}$ only. 26 patients, comprising control subgroup, did not receive any additional antiCAMR treatment. Evaluation of treatment efficacy was performed by comparison of 3-years renal allografts Kaplan-Mayer survival curves between treatment subgroup and control subgroup. Kidney transplant function was estimated by serum creatinine level and eGFR, calculated by Cocroft-Gault equation. Rate of allograft function loss was calculated as delta eGFR per month [eGFR at the end of follow-up - baseline eGFR/duration of follow-up (months)].

\section{Statistics}

Statistical analysis was performed using SPSS 11.5 program package. Normally distributed variables presented as the mean \pm standard deviation (SD). Comparison between mean data performed using Student criteria. Differences significance for categorical variables was evaluated by Fisher's exact test and $\chi^{2}$ test. For abnormally distributed variables median value and interquartile range were calculated, MannWhitney test and Kruskall-Wallis test were used for comparison of these variables. P-value $<0.05$ was defined for statistical significance.

\section{Results}

Overall allografts survival at the end of 3 years follow-up period after the diagnosis was low - $41.2 \%$. Iinterestingly, in patients with chronic rejection there were no differences in the allografts survival depending on C4d focal or diffuse expression and/or concomitant cell-mediated rejection, which was found in 13 patients [in 7 cases interstitial (Banff $1 \mathrm{a}-\mathrm{b}$ ) and in 6 - vascular (Banff 2a)] (Figure 1). During the follow-up period study group demonstrated progressive loss of renal transplant function: eGFR declined from $43.1 \pm 18.3 \mathrm{ml} /$ min at the time of diagnosis to $33.6 \pm 18.9 \mathrm{ml} / \mathrm{min}$ to the end of the study period. At the time of diagnosis baseline eGFR did not differ between treatment and control subgroups $(44.9 \pm 21.3$ vs $41.2 \pm 14.6$ $\mathrm{ml} / \mathrm{min}, \mathrm{P}=0.47$ ), and subsequent decline of allografts function was also found in both subgroups.

However, the rate of eGFR decline was significantly lower in patients from the treatment subgroup compared to the controls: -0.47 $\pm 0.6 \mathrm{ml} / \mathrm{min} / \mathrm{month}$ and $-1.31 \pm 1.6 \mathrm{ml} / \mathrm{min} / \mathrm{month}$ respectively $(\mathrm{P}=0.02)$ (Figure 2).

Totally 22 allografts were lost during the follow-up period, 15 in the control subgroup and only 7 in the treatment subgroup. Thus, 3-year transplant survival turned to be $21.3 \%$ in the control subgroup vs $64.8 \%$ in the treatment subgroup $(\mathrm{P}=0.01)$ (Figure 3$)$. Multivariate Cox Regression model analysis revealed that only baseline eGFR and treatment modality were independent prognostic factors for the transplant function (Table 2). Other factors - demographic or clinical, like patient's age, time after renal transplantation and level of proteinuria, as well as pathology characteristics (C4d staining pattern, severity of TG, extent of interstitial fibrosis or proportion of totally sclerotic glomeruli) did not influence prognosis independently. Infectious complications were observed in both treatment and control subgroups, the differences were not significant. Treatment side effects occurred only in treatment subgroup, and were presented by allergic reactions, hypoproteinemia and leukopenia (Table 3 ). Totally 4 patients died during the study period: 2 in the treatment subgroup ( 1 from pneumonia and 1 from stroke), and 2 in the control subgroup (1 from pneumonia and 1 from infectious endocarditis).

\section{Discussion}

Recent studies showed that TG is the most often type of CAMR, characterized by unfavorable prognosis and rapid progression towards end stage of renal disease (ESRD). Allograft survival data in our study are completely consistent with the current view, as 3-year survival in our group of patients was found as low as $41.2 \%$. That is even lower than in the study, performed by Gloor et al. [15], who described natural history of TG in 55 patients. The difference in survival rate might be caused by less severe baseline damage with predominantly sub-clinical course in patients from Gloor's cohort. Other studies with inclusion of clinically overt TG cases demonstrated lower allografts survival, which was not $>50 \%$ to the end of 2-years follow-up $[16,17]$ similarly to our data. Generally speaking the course of TG may significantly differ due 
Citation: Stolyarevich ES, Artyukhina LA, Zakharova EV, Tomilina NA. (2016) Combined Treatment with Plasma Exchanges, Intravenous Immunoglobulin and Rituximab (One Center Experience). J Nephrol Ther 6: 243. doi:10.4172/2161-0959.1000243

Page 3 of 6

\begin{tabular}{|c|c|c|c|c|}
\hline & Total $(n=50)$ & $P E / I V I G / R x(n=24)$ & Control $(n=26)$ & $\mathbf{P}$ \\
\hline Age (mean $\pm S D$, years) & $40.6 \pm 12.5$ & $42.7 \pm 12.0$ & $38.7 \pm 12.9$ & NS \\
\hline Time from transplantation (mean $\pm S D$, months) & $81.4 \pm 51.8$ & $82.6 \pm 67.5$ & $80.4 \pm 49.1$ & NS \\
\hline Serum creatinine $($ mean $\pm S D$ mmol/l) & $0.21 \pm 0.08$ & $0.2 \pm 0.06$ & $0.2 \pm 0.09$ & NS \\
\hline GFR (mean $\pm S D, m l / m i n)$ & $43.1 \pm 18.3$ & $41.2 \pm 14.6$ & $44.9 \pm 21.3$ & NS \\
\hline Proteinuria (mean $\pm S D, g /$ day) & $2.07 \pm 1.9$ & $2.6 \pm 2.1$ & $1.7 \pm 1.7$ & NS \\
\hline \multicolumn{5}{|l|}{ Anti-HLA antibodies } \\
\hline Positive class I & $4(8 \%)$ & $2(8 \%)$ & $2(8 \%)$ & \multirow{4}{*}{ NS } \\
\hline Positive class II & $30(60 \%)$ & $16(67 \%)$ & $14(54 \%)$ & \\
\hline Positive class I+II & $12(24 \%)$ & $5(21 \%)$ & $7(27 \%)$ & \\
\hline Negative & $4(8 \%)$ & $1(4 \%)$ & $3(11 \%)$ & \\
\hline \multicolumn{5}{|l|}{ Transplant glomerulopathy (cg) } \\
\hline 1 & $24(48 \%)$ & $12(50 \%)$ & $12(46 \%)$ & \multirow{4}{*}{ NS } \\
\hline 2 & $20(40 \%)$ & $8(33 \%)$ & $12(46 \%)$ & \\
\hline 3 & $6(12 \%)$ & $4(17 \%)$ & $2(8 \%)$ & \\
\hline mean score & $1.6 \pm 0.7$ & $1.7 \pm 0.8$ & $1.6 \pm 0.6$ & \\
\hline \multicolumn{5}{|l|}{ C4d on PTC n (\%) } \\
\hline Negative & $15(30 \%)$ & $6(25 \%)$ & $9(35 \%)$ & \multirow{3}{*}{ NS } \\
\hline Focal & $9(18 \%)$ & $3(13 \%)$ & $6(23 \%)$ & \\
\hline Diffuse & $26(52 \%)$ & $15(62 \%)$ & $11(42 \%)$ & \\
\hline \multicolumn{5}{|l|}{ Peritubular capillaritis } \\
\hline 0 & $19(38 \%)$ & $8(33 \%)$ & $11(42 \%)$ & \multirow{5}{*}{ NS } \\
\hline 1 & $19(38 \%)$ & $11(46 \%)$ & $8(31 \%)$ & \\
\hline 2 & $9(18 \%)$ & $4(17 \%)$ & $5(19 \%)$ & \\
\hline 3 & $3(6 \%)$ & $1(4 \%)$ & $2(8 \%)$ & \\
\hline mean score & $0.92 \pm 0.9$ & $0.92 \pm 0.9$ & $0.92 \pm 1.0$ & \\
\hline \multicolumn{5}{|l|}{ Glomerulitis } \\
\hline 0 & $8(16 \%)$ & $3(13 \%)$ & $5(19 \%)$ & \multirow{5}{*}{ NS } \\
\hline 1 & $25(50 \%)$ & $13(54 \%)$ & $12(46 \%)$ & \\
\hline 2 & $10(20 \%)$ & $6(25 \%)$ & $4(16 \%)$ & \\
\hline 3 & $7(14 \%)$ & $2(8 \%)$ & $5(19 \%)$ & \\
\hline mean score & $1.32 \pm 0.9$ & $1.29 \pm 0.8$ & $1.35 \pm 1.0$ & \\
\hline \multicolumn{5}{|l|}{ Intimal arteriitis $\mathrm{n}(\%)$} \\
\hline 0 & $44(88 \%)$ & $22(92 \%)$ & $22(85 \%)$ & \multirow{4}{*}{ NS } \\
\hline 1 & $6(12 \%)$ & $2(8 \%)$ & $4(15 \%)$ & \\
\hline 2 & 0 & 0 & 0 & \\
\hline 3 & 0 & 0 & 0 & \\
\hline \multicolumn{5}{|l|}{ Tubulitis } \\
\hline 0 & $26(52 \%)$ & $16(67 \%)$ & $10(39 \%)$ & \multirow{4}{*}{ NS } \\
\hline 1 & $13(26 \%)$ & $4(16 \%)$ & $9(34 \%)$ & \\
\hline 2 & $9(18 \%)$ & $3(13 \%)$ & $6(23 \%)$ & \\
\hline \multirow[t]{2}{*}{3} & $2(4 \%)$ & $1(4 \%)$ & $1(4 \%)$ & \\
\hline & $0.74 \pm 0.9$ & $0.54 \pm 0.9$ & $0.92 \pm 0.9$ & \\
\hline Glomerulosclerosis (\%) & $22.4 \pm 25.3$ & $14.8 \pm 20.1$ & $28.8 \pm 27.6$ & 0.05 \\
\hline Interstitial fibrosis (\%) & $25.6 \pm 18.3$ & $23.8 \pm 14.9$ & $27.4 \pm 21.2$ & \multirow{2}{*}{ NS } \\
\hline (Banff score) & $1.54 \pm 0.9$ & $1.54 \pm 0.8$ & $1.54 \pm 0.9$ & \\
\hline
\end{tabular}

Table 1: Demographics, laboratory data and pathology.

to the heterogeneity of its pathology features. Despite of clearly defined pathology criteria for the diagnosis, pathology findings in CAMR may vary depending on TG stage, interstitial fibrosis extent, presence and type of C4d PTC positivity, and also presence and severity of concomitant cell-mediated rejection. In our patients all these peculiarities correlated with clinical manifestations of allograft rejection, however, we did not find any single pathology feature, directly influencing TG course and long-term outcomes. In particular, a concomitant cell-mediated rejection demanding high-dose steroid, which was found in 13 patients in our study group, finally did not influence significantly the outcomes.
There were also no differences in allografts survival depending on the extent rejection activity, evaluated by the type of C4d expression.

According to the Banff classification, only diffuse C4d expression on PTC is considered as diagnostic for AMR [3], as that strongly correlate with DSA production and outcomes. However, these correlations were demonstrated first of all for acute AMR, whereas in CAMR C4d-positivity is seen not so often, and do not influence the course of the disease that much. Thus, the study performed by Haririan et al. did not show significant differences in the course of rejection depending on type of C4d positivity [18]; other investigators noticed 
Citation: Stolyarevich ES, Artyukhina LA, Zakharova EV, Tomilina NA. (2016) Combined Treatment with Plasma Exchanges, Intravenous Immunoglobulin and Rituximab (One Center Experience). J Nephrol Ther 6: 243. doi:10.4172/2161-0959.1000243

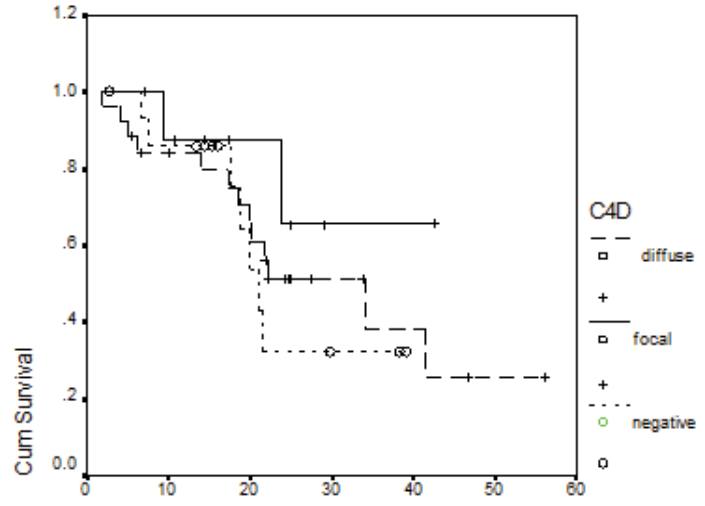

months after biopsy

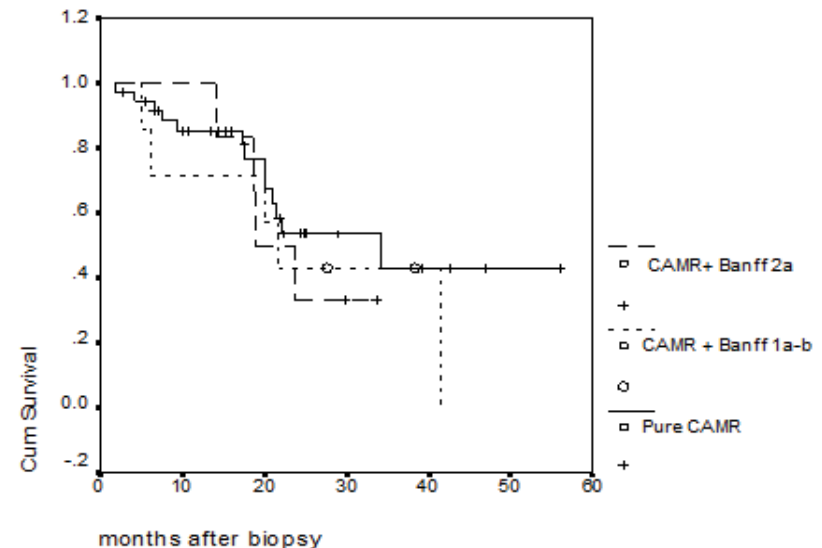

B)

Figure 1: Graft survival according to the presence and character of $C 4 d$ staining $(A)$ and concomitant cell- mediated rejection (B).

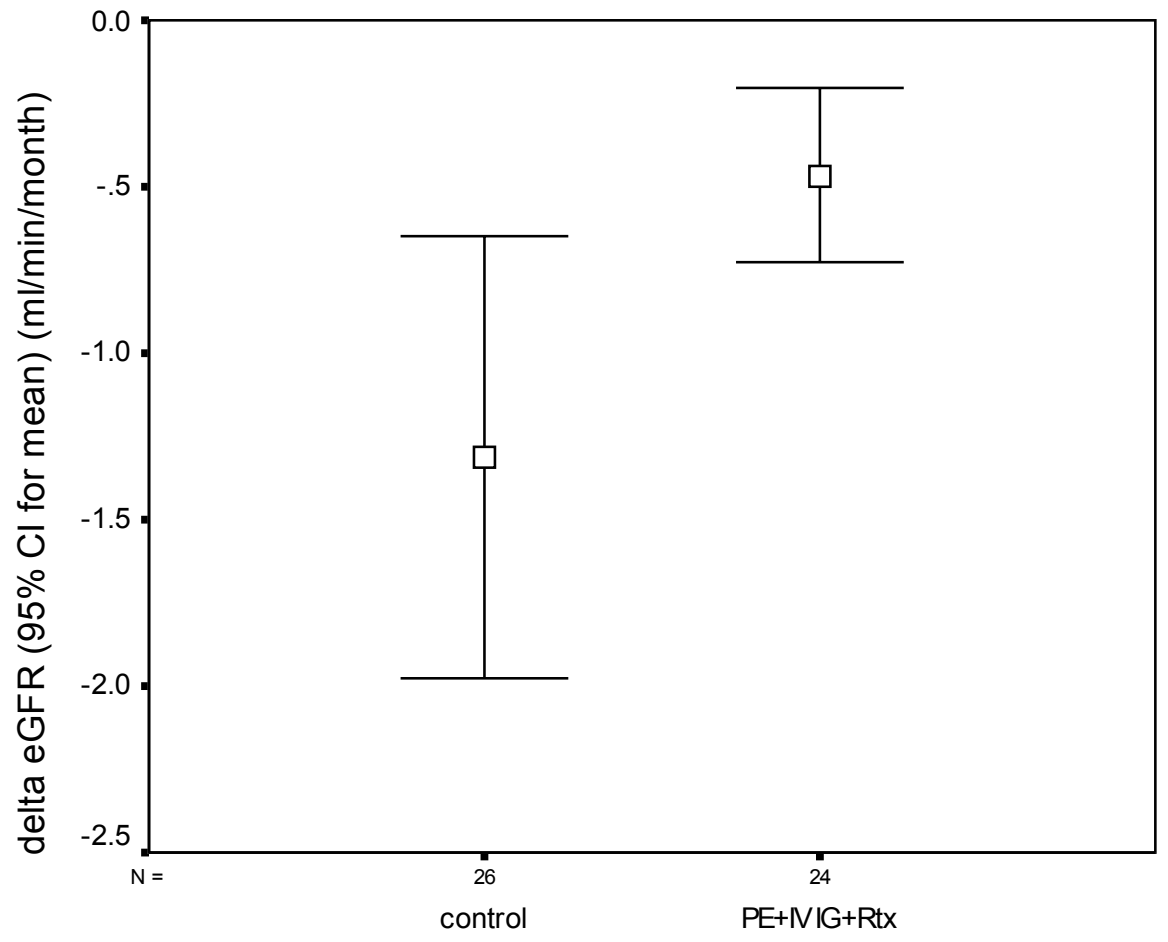

Figure 2: The rate of eGFR decline, calculated as delta eGFR per month [eGFR at the end of follow-up baseline eGFR/duration of follow-up (months)].

more favorable prognosis in patients with focal C4d expression [19]. In our study outcomes of TG were equally unfavorable both in cases with diffuse and focal C4d expression, which lead us to regard focal C4dpositivity as AMR criteria (same as diffuse C4d expression). Therefore, AMR prognosis in our patients did not depend on pathology findings, demanding the same treatment strategy regardless of its stage and activity.

Current approach to the AMR treatment includes measures directed to the already existing anti-donor antibodies elimination, and prevention of their further production. To achieve these goals most often PE, IVIG and Rtx (anti CD20-antibodies) are used in different regimens and combinations. That strategy already demonstrated its 
Citation: Stolyarevich ES, Artyukhina LA, Zakharova EV, Tomilina NA. (2016) Combined Treatment with Plasma Exchanges, Intravenous Immunoglobulin and Rituximab (One Center Experience). J Nephrol Ther 6: 243. doi:10.4172/2161-0959.1000243

Page 5 of 6

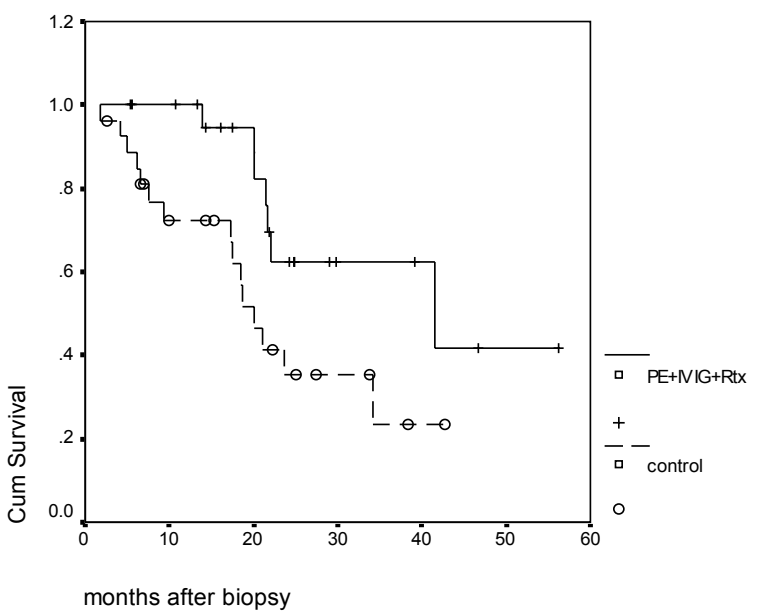

Figure 3: Graft survival according to according to the treatment strategy.

\begin{tabular}{|c|c|c|c|c|}
\hline & P value & OR & $95.0 \% \mathbf{C l}$ & \\
\hline & & & Lower & Upper \\
\hline Treatment modality & 0.002 & 0.1 & 0.026 & 0.439 \\
\hline Transplant glomerulopathy & 0.398 & 0.64 & 0.232 & 1.787 \\
\hline Interstitial fibrosis & 0.263 & 1.02 & 0.985 & 1.056 \\
\hline Glomerulosclerosis & 0.12 & 0.97 & 0.937 & 1.008 \\
\hline C4D pattern & 0.765 & 0.9 & 0.446 & 1.811 \\
\hline Patient's age & 0.789 & 1 & 0.955 & 1.062 \\
\hline Time after renal transplantation & 0.749 & 1 & 0.99 & 1.015 \\
\hline Cellular rejection & 0.27 & 1.5 & 0.711 & 3.389 \\
\hline Proteinuria & 0.557 & 1.1 & 0.809 & 1.482 \\
\hline eGFR & 0.01 & 0.94 & 0.909 & 0.987 \\
\hline
\end{tabular}

Table 2: Cox regression model.

efficacy in the treatment of acute AMR episodes [7-10]. In contrast, already developed chronic TG is characterized by the resistance to the treatment. Only few studies, approaching this issue, are published so far, and the results of these studies are controversial. These are mainly small patient's series, demonstrating partial effect of treatment with transplant function stabilization in some cases. Thus, Billing et al. used the combination of IVIG $(1 \mathrm{~g} / \mathrm{kg})$ and Rtx $\left(325 \mathrm{mg} / \mathrm{m}^{2}\right)$ and found stabilization of transplant function in 14 out of 20 children with active AMR [12]. Similar efficacy demonstrated the study, performed by Fehr et al. in 4 adult patients [13]. Kayler et al. describe delay of eGFR decline during 6 months after IVIG and Rtx treatment in 12 out of 18 patients with CAMR, compared to the rate of eGFR decline in the same patients during 6 months before that treatment [20]. The number of patients in above mentioned studies was 20 as maximum. Although in our study a small sample size is the main limitation, it included 50 patients and found statistically significant differences in the rate of transplant function decline as well as in the transplant loss proportion between the treatment and control subgroups. Moreover, post-hoc power calculation showed study power $69 \%$.

Majority of authors, who used different treatment strategies

\begin{tabular}{|c|c|c|c|}
\hline & $\begin{array}{c}\text { Treatment } \\
\text { subgroup }\end{array}$ & $\begin{array}{c}\text { Control } \\
\text { subgroup }\end{array}$ & P \\
\hline Infectious complications & $8(33 \%)$ & $4(16 \%)$ & NS \\
\hline Acute bronchitis & 1 & 0 & \\
\hline Bacterial pneumonia & 5 & 1 & \\
\hline CMV-pneumonia & 1 & 0 & \\
\hline Infectious endocarditis & 0 & 1 & \\
\hline Tuberculosis & 0 & 1 & \\
\hline Soft tissues infection & 0 & 1 & \\
\hline Erysipelas & 1 & 0 & \\
\hline Non-infectious complications/side effects & $6(25 \%)$ & 0 & $<0.05$ \\
\hline Allergic reaction after Fresh Frozen Plasma & 2 & 0 & \\
\hline infusion & 1 & 0 & \\
\hline Hypoproteinemia & 2 & 0 & \\
\hline Leukopenia & 1 & 0 & \\
\hline Stroke & $14(58 \%)$ & $4(16 \%)$ & $<0.05$ \\
\hline Total & & \\
\hline
\end{tabular}

Table 3: Complications and side effects.

for CAMR, found the effect only in some patients, but not in all of them, however, none of the studies were able to identify the factors, defining the response to treatment. Whereupon several causes that might explain treatment resistance are known. Prominent structural changes of capillary walls, characteristic for the late stages of CAMR and presenting with severe proteinuria, progress to ESRD even in the absence of immune activity [21,22]. On the other hand, predominance of B-memory cells and plasma cells in adults, compare to children, make the former less susceptible to Rtx treatment [23]. Despite majority of authors consider futility of anti-humoral therapy in CAMR, it is difficult to access true efficacy of such treatment in the above mentioned studies. The main pitfall is the absence of control groups, because the natural history of TG is characterized by alternating of progression and stabilization periods. Recently published study, conducted by Bachelet et al., also favors this hypothesis, demonstrating no difference in 2-year survival between patients, receiving IVIG and Rtx and control group (47\% and $40 \%$ respectively, $\mathrm{P}=0.69$ ) [16]. Our study with the similar design and compatible clinical and pathology characteristic's of patients population, however demonstrated significant differences in allograft survival between subgroups - $64.8 \%$ vs $21.3 \% \quad(\mathrm{P}=0.01)$. Possible explanation might be including of PE to the treatment protocol, as PE rapidly eliminate anti-donor antibodies and potentiate IVIG effects. Although PE, according to Cedar-Sinai Medical Center protocol [7], is considered to be necessary only if humoral rejection is accompanied by thrombotic microangiopathy, Lefaucheur et al. demonstrated the benefit of combination of PE, IVIG and Rtx compared to only IVIG and Rtx usage [24]. Interestingly, that the point of no-return for CAMR seems to be 2 years in our study 5 out of 7 allograft losses in the treatment subgroup occurred in the interval between 20 and 22 month after the treatment initiation. We suppose that 2 -years follow-up period, which is often used for assessment of treatment results, may be not sufficient for accurate evaluation of CAMR therapy efficacy.

\section{Conclusions}

Our study demonstrated, that TG, which is the most often variant of CAMR, is characterized by unfavorable prognosis regardless of its pathology features and activity at the time of diagnosis. Combined treatment, including PE, IVIG and Rtx allows slowing down the rate of the disease progression at least in some proportion of patients with lately diagnosed CAMR. 
Citation: Stolyarevich ES, Artyukhina LA, Zakharova EV, Tomilina NA. (2016) Combined Treatment with Plasma Exchanges, Intravenous Immunoglobulin and Rituximab (One Center Experience). J Nephrol Ther 6: 243. doi:10.4172/2161-0959.1000243

\section{References}

1. Colvin RB (2011) Diagnostic Pathology: Kidney Diseases. Amirsys.

2. Colvin RB, Nickeleit V (2006) Heptinstall's Pathology of the Kidney. In: Jennette JC, Olson JL, Schwartz MM, Silva FG (eds.) Lippincott-Raven, Philadelphia, pp: $1347-1490$

3. Racusen LC, Colvin RB, Solez K, Mihatsch MJ, Halloran PF, et al. (2003) Antibody-mediated rejection criteria - an addition to the Banff 97 classification of renal allograft rejection. Am J Transplant 3: 708-714.

4. Sis B, Mengel M, Haas M, Colvin RB, Halloran PF, et al. (2010) Banff '09 meeting report: antibody mediated graft deterioration and implementation of Banff working groups. Am J Transplant 10: 464-471.

5. Gloor J, Cosio F, Lager DJ, Stegall MD (2008) The spectrum of antibodymediated renal allograft injury: implications for treatment. Am J Transplant 8 : 1367-1373.

6. Sis B, Campbell PM, Mueller T, Hunter C, Cockfield SM, et al. (2007) Transplan glomerulopathy, late antibody-mediated rejection and the ABCD tetrad in kidney allograft biopsies for cause. Am J Transplant 7: 1743-1752.

7. Jordan SC, Quartel AW, Czer LS, Admon D, Chen G, et al. (1998) Posttransplan therapy using high-dose human immunoglobulin (intravenous gammaglobulin) to control acute humoral rejection in renal and cardiac allograft recipients and potential mechanism of action. Transplantation 66: 800-805.

8. Everly MJ, Everly JJ, Arend LJ, Brailey P, Susskind B, et al. (2009) Reducing De Novo Donor-Specific Antibody Levels during Acute Rejection Diminishes Renal Allograft Loss. Am J Transplant 9: 1063-1071.

9. Montgomery RA, Zachary AA, Racusen LC, Leffell MS, King KE, et al. (2000) Plasmapheresis and intravenous immune globulin provides effective rescue therapy for refractory humoral rejection and allows kidneys to be successfully transplanted into cross-match-positive recipients. Transplantation 70: 887-895.

10. Rocha PN, Butterly DW, Greenberg A, Reddan DN, Tuttle-Newhall J, et al. (2003) Beneficial effect of plasmapheresis and intravenous immunoglobulin on renal allograft survival of patients with acute humoral rejection. Transplantation 75: 1490-1495

11. Smith RN, Malik F, Goes N, Farris AB, Zorn E, et al. (2012) Partial therapeutic response to Rituximab for the treatment of chronic alloantibody mediated rejection of kidney allografts. Transpl Immunol 27: 107-113.

12. Billing H, Rieger S, Süsal C, Waldherr R, Opelz G, et al. (2012) IVIG and rituximab for treatment of chronic antibody-mediated rejection: a prospective study in paediatric renal transplantation with a 2-year follow-up. Transpl Int 25 $1165-1173$.
3. Fehr T, Rüsi B, Fischer A, Hopfer H, Wüthrich RP, et al. (2009) Rituximab and intravenous immunoglobulin treatment of chronic antibody-mediated kidney allograft rejection. Transplantation 87: 1837-1841.

14. Rostaing L, Guilbeau-Frugier C, Fort M, Mekhlati L, Kamar N (2009) Treatmen of symptomatic transplant glomerulopathy with rituximab. Transpl Int 22: 906913.

15. Gloor JM, Sethi S, Stegall MD, Park WD, Moore SB, et al. (2007) Transplant glomerulopathy: subclinical incidence and association with alloantibody. Am J Transplant 7: 2124-2132.

16. Bachelet T, Nodimar C, Taupin JL, Lepreux S, Moreau K, et al. (2015) Intravenous immunoglobulins and rituximab therapy for severe transplant glomerulopathy in chronic antibody-mediated rejection: a pilot study. Clin Transplant 29: 439-446.

17. Kieran N, Wang X, Perkins J, Davis C, Kendrick E, et al. (2009) Combination of peritubular c4d and transplant glomerulopathy predicts late renal allograft failure. J Am Soc Nephrol 20: 2260-2268.

18. Haririan A, Kiangkitiwan B, Kukuruga D, Cooper M, Hurley H, et al. (2009) The impact of c4d pattern and donor-specific antibody on graft survival in recipients requiring indication renal allograft biopsy. Am J Transplant 9: 2758-2767.

19. Kedainis RL, Koch MJ, Brennan DC, Liapis H (2009) Focal C4d+ in renal allografts is associated with the presence of donor-specific antibodies and decreased allograft survival. Am J Transplant 9: 812-819.

20. Kayler LK, Kiss L, Sharma V, Mohanka R, Zeevi A, et al. (2008) Acute rena allograft rejection: diagnostic significance of focal peritubular capillary C4d. Transplantation 85: 813-820.

21. Hong YA, Kim HG, Choi SR, Sun IO, Park HS, et al. (2012) Effectiveness of rituximab and intravenous immunoglobulin therapy in renal transplant recipients with chronic active antibody-mediated rejection. Transplant Proc 44: 182-184.

22. An GH, Yun J, Hong YA, Khvan M, Chung BH, et al. (2014) The effect of combination therapy with rituximab and intravenous immunoglobulin on the progression of chronic antibody mediated rejection in renal transplant recipients. J Immunol Res 1-7.

23. Zarkhin V, Lovelace PA, Li L, Hsieh SC, Sarwal MM (2011) Phenotypic evaluation of B-cell subsets after rituximab for treatment of acute renal allograft rejection in pediatric recipients. Transplantation 91: 1010-1018.

24. Lefaucheur C, Nochy D, Andrade J, Verine J, Gautreau C, et al. (2009) Comparison of combination Plasmapheresis/IVIg/anti-CD20 versus high-dose $\mathrm{IVIg}$ in the treatment of antibody-mediated rejection. Am J Transplant 9: 10991107. 